\title{
OPTIMALISASI KEUNTUNGAN DENGAN MENGGUNAKAN ALGORITMA BRANCH AND BOUND PADA PT XYZ
}

\author{
Nintia Litano ${ }^{1}$, Endang Suhendar ${ }^{2}$ \\ Program Studi Teknik Industri, Universitas Indraprasta PGRI Jakarta ${ }^{1}$ \\ dinilitano@gmail.com, endang_suhendar@unindra.ac.id
}

Submitted January 21, 2020; Revised March 22, 2020; Accepted June 8, 2020

\begin{abstract}
Abstrak
Dalam memaksimalkan keuntungan yang akan diperoleh perusahaan perlu adanya perencanaan produksi yang optimal. Perencanaan tersebut mempertimbangkan ketersediaan sumber daya pada perusahaan. PT XYZ merupakan perusahaan yang bergerak di bidang furniture. Penelitian ini fokus kepada pengoptimalan perencanaan produksi pada pembuatan produk pintu di PT.XYZ. Terdapat beberapa jenis produk yang diproduksi di antaranya: Pintu tipe D1, Pintu tipe D2, Pintu tipe D3, dan Pintu tipe D4. Perencanaan produksi di PT.XYZ ini dapat dikatakan sebagai model program integer, karena semua variabel menghendaki hasilnya berupa bilangan bulat. Program tersebut berhubungan dengan pengoptimalan ketersediaan sumber daya bertujuan untuk memaksimalkan keuntungan. Pengoptimalan yang dilakukan yaitu dengan menentukan jumlah produksi untuk masing-masing tipe serta mempertimbangkan semua ketersediaan sumber daya yang ada. Pencarian solusi untuk model ini dilakukan dengan algoritma Branch and Bound. Berdasarkan hasil perhitungan menggunakan software QM for Windows, diketahui bahwa penentuan jumlah produksi dengan menggunakan algoritma Branch and Bound memberikan peningkatan keuntungan sebesar 36.5\% dibandingkan dengan keuntungan PT.XYZ sebelumnya.
\end{abstract}

Kata Kunci: Optimasi, program integer, Branch and Bound

\begin{abstract}
In maximizing the profits to be obtained the company needs optimal production planning. The plan considers the resources of the company. PT XYZ is a furniture company. This research focuses on optimizing production planning on the manufacture of door products at PT. XYZ. There are several types of products issued in: D1 type door, D2 type door, D3 type door, and D4 type door. Production planning at PT. XYZ can be seen as an integer program model, which is a method related to optimizing resources to increase profits. Optimization is done by determining the amount of production for each type and each calculating existing resources. The solution search for this model is done by the Branch and Bound algorithm. Based on the calculation results using QM software for Windows, the amount corresponding to production is obtained by using Branches and Bound giving an increase of $36.5 \%$ compared to the acquisition of PT. XYZ before.
\end{abstract}

Key Words: Optimization, integer programming, Branch and Bound.

\section{PENDAHULUAN}

Perencanaan produksi penting dalam berlangsungnya manajemen perusahaan, agar penjual dapat mengetahui jenis dan jumlah produk yang akan diproduksi dan dijual sesuai dengan permintaan konsumen. Manajemen produksi merupakan kegiatan untuk mengatur penggunaan sumber daya secara efektif dan efisien untuk menciptakan dan menambah kegunaan (utility) sesuatu barang atau jasa [1].

PT XYZ merupakan sebuah perusahaan yang bergerak dalam bidang furniture interior design yang berlokasi di Jl. Raya Cileungsi-Jonggol, Kecamatan Cileungsi, Kabupaten Bogor. Usaha ini tidak memiliki metode yang pasti dalam 
menentukan jumlah produksi yang optimal pada masing-masing tipe pintu. Pada PT $\mathrm{XYZ}$ terdapat kendala-kendala yang terjadi dalam proses produksi di antara nya yaitu ketersediaan bahan baku yang digunakan, waktu produksi yang diperlukan, jumalah tenaga kerja yang ada mempengaruhi jumlah produksi yang dihasilkan, kemampuan kapasitas produksi, dan jumlah permintaan produk yang beragam.

Kendala-kendala yang terjadi pada PT XYZ dapat dikatakan sebagai integer programming dikarenakan semua variabel menghendaki hasilnya berupa bilangan bulat. Sesuai dengan namanya metode ini membatasi penyelesaian optimal yang akan menghasilkan bilangan pecahan dengan cara membuat cabang atas atau bawah bagi masing-masing variabel keputusan yang bernilai bulat sehingga setiap oembatasan akan menghasilkan cabang baru [2]. Pada penelitian ini dengan menggunakan algoritma Branch and Bound efektif dan sederhana untuk menyelesaikan model program integer [3]-[6].

Dengan prinsip kerja metode Branch and Bound yaitu mencabangkan variabel keputusan yang tidak memiliki penyelesaian bulat, percabangan dilakukan terus hingga diperoleh penyelesaian bulat sehingga semua variabel keputusannya bernilai bulat dan menghasilkan keuntungan maksimal bagi perusahaan [6]. Maka dari itu pada penelitian ini, peneliti mencoba menghitung sebuah optimalisasi hasil produksi dalam produksi pembuatan pintu pada PT XYZ menggunakan menggunakan Integer Linear Programming (ILP) dengan metode Branch and Bound.

Suatu masalah optimasi, dikenal fungsi objektif atau fungsi tujuan yang merupakan fungsi pengevaluasi yang ingin dioptimalkan [7]. Program integer digunakan untuk memodelkan permasalahan yang variabel-variabelnya tidak mungkin berupa bilangan yang tidak bulat (bilangan riil) [8]. Menurut [9]
Algoritma branch and bound adalah pendekatan solusi yang membagi ruang solusi yang layak menjadi himpunan bagian solusi yang lebih kecil. Algoritma branch and bound dilakukan secara berulang hingga membentuk pohon pencarian (search tree) dan dilakukan proses pembatasan (bounding) dengan menentukan batasan (bounding) dalam mencari solusi optimal [10].

\section{METODE PENELITIAN}

Dalam penelitian ini metode yang digunakan yaitu dengan melakukan studi pustaka melalui buku maupun penelitian yang terdahulu dalam konsep algoritma Branch and Bound dan model Integer Linear Programing. Kemudian diimplementasi pada PT XYZ untuk penentuan jumlah produksi yang optimal untuk memaksimalkan keuntungan. Pengolahan data dilakukan dengan menggunakan perangkat lunak $Q M$ for Windows. Hasil dari pengolahan data dan analisis diharapkan dapat menjadi solusi dari keputusan penentuan jumlah produksi yang optimal.

\section{HASIL DAN PEMBAHASAN}

Pada pengolahan data dalam menyelesaikan permasalahan pada PT XYZ untuk memaksimalkan keuntungan produksi dibutuhkan pengumpulan data yang lengkap mengenai proses produksi seluruh tipe pintu.

Pada PT XYZ terdapat beberapa tipe pintu yaitu antara lain pintu tipe D1, D2, D3, dan D4. Dalam rangka memaksimalkan keuntungan, perusahaan harus menentukan jumlah produksi pintu tiap tipe yang sebaiknya diproduksi. Pada penelitian ini, yang merupakan variabel keputusan adalah Pintu D1 $\left(\mathrm{x}_{1}\right)$, Pintu D2, $\left(\mathrm{x}_{2}\right)$, Pintu D3 $\left(\mathrm{x}_{3}\right)$, Pintu D4 $\left(\mathrm{x}_{4}\right)$. Berikut adalah uraian permasalahan yang biasa terkendala pada PT XYZ: 
Tabel 1. Uraian Kendala PT XYZ

\begin{tabular}{|c|c|c|c|c|c|c|}
\hline $\begin{array}{c}\text { Uraian } \\
\text { Kendala }\end{array}$ & $\begin{array}{c}\text { Pintu } \\
\text { D1 }\end{array}$ & $\begin{array}{l}\text { Pintu } \\
\text { D2 }\end{array}$ & $\begin{array}{c}\text { Pintu } \\
\text { D3 }\end{array}$ & $\begin{array}{l}\text { Pintu } \\
\text { D4 }\end{array}$ & Kapasitas & Satuan \\
\hline Keuntungan & 161.2 & 100.5 & 115 & 130 & & \\
\hline Kayu & 20 & 20 & 20 & 6 & 1000 & $\mathrm{~m}^{2}$ \\
\hline Kaca & - & - & - & 6 & 50 & $\mathrm{~m}^{2}$ \\
\hline $\begin{array}{c}\text { Gagang } \\
\text { pintu }\end{array}$ & 1 & 1 & 1 & 1 & 300 & Pcs \\
\hline Engsel & 2 & 2 & 2 & 2 & 600 & Pcs \\
\hline Cat & 2 & 2 & 2 & 2 & 15 & $\mathrm{Kg}$ \\
\hline $\begin{array}{c}\text { Waktu } \\
\text { Produksi }\end{array}$ & 100 & 100 & 100 & 100 & 2880 & Menit \\
\hline $\begin{array}{l}\text { Tenaga } \\
\text { kerja }\end{array}$ & 5 & 5 & 5 & 5 & 60 & Pekerja \\
\hline Mesin & 2 & 2 & 2 & 2 & 16 & Mesin \\
\hline $\begin{array}{l}\text { Permintaan } \\
\text { D1 }\end{array}$ & 480 & 0 & 0 & 0 & 1200 & Pcs \\
\hline $\begin{array}{l}\text { Permintaan } \\
\text { D2 }\end{array}$ & 0 & 1128 & 0 & 0 & 1200 & Pcs \\
\hline $\begin{array}{l}\text { Permintaan } \\
\text { D3 }\end{array}$ & 0 & 0 & 648 & 0 & 1200 & Pcs \\
\hline $\begin{array}{l}\text { Permintaan } \\
\text { D4 }\end{array}$ & 0 & 0 & 0 & 480 & 1200 & Pcs \\
\hline $\begin{array}{l}\text { Kapasitas } \\
\text { produksi }\end{array}$ & 1 & 1 & 1 & 1 & 1200 & Pcs \\
\hline
\end{tabular}

Setelah mendefinisikan variabel keputusan dan mengetahui uraian kendala, maka langkah selanjutnya adalah menentukan Fungsi Tujuan dan Fungsi Kendala dari penelitian, sebagai berikut:

Fungsi Tujuan:

$\mathrm{Z}_{\text {maks }}=161200 \mathrm{x}_{1}+100500 \mathrm{x}_{2}+115000 \mathrm{x}_{3}+$ $130000 x_{4}$

Fungsi Kendala :

$20 \mathrm{x}_{1}+20 \mathrm{x}_{2}+20 \mathrm{x}_{3}+6 \mathrm{x}_{4} \leq 1000$

(Kayu)

$6 \mathrm{x}_{4}$ $\leq 50$

(Kaca)

$\mathrm{x}_{1}+\mathrm{x}_{2}+\mathrm{x}_{3}+\mathrm{x}_{4}$

(Gagang pintu)

$2 \mathrm{x}_{1}+2 \mathrm{x}_{2}+2 \mathrm{x}_{3}+2 \mathrm{x}_{4}$ $\leq 600$

(Engsel pintu)

$100 \mathrm{x}_{1}+100 \mathrm{x}_{2}+100 \mathrm{x}_{3}+100 \mathrm{x}_{4} \leq 2880$

(Waktu)

$2 \mathrm{x}_{1}+2 \mathrm{x}_{2}+2 \mathrm{x}_{3}+2 \mathrm{x}_{4}$

$\leq \quad 15$

(Cat)

$2 \mathrm{x}_{1}+2 \mathrm{x}_{2}+2 \mathrm{x}_{3}+2 \mathrm{x}_{4} \leq 16$

(Mesin)
$5 \mathrm{x}_{1}+5 \mathrm{x}_{2}+5 \mathrm{x}_{3}+5 \mathrm{x}_{4}$

$\leq 60$

(Tenaga Kerja)

$\mathrm{x}_{1}+\mathrm{x}_{2}+\mathrm{x}_{3}+\mathrm{x}_{4}$

$\leq 1200$

(Kapasitas Produksi)

$480 \mathrm{x}_{1} \leq 1200 \quad$ (Permintaan Tipe D1)

$1128 \mathrm{x}_{2} \leq 1200$ (Permintaan Tipe D2)

$648 \mathrm{x}_{3} \leq 1200 \quad$ (Permintaan Tipe D3)

$480 \mathrm{x}_{4} \leq 1200 \quad$ (Permintaan Tipe D4)

$\mathrm{x}_{1}, \mathrm{x}_{2}, \mathrm{x}_{3}, \mathrm{x}_{4}$

$\mathrm{x}_{1}, \mathrm{x}_{2}, \mathrm{x}_{3}, \mathrm{x}_{4}$

C I

Kemudian setelah mengetahui secara matematis Fungsi Tujuan dan Fungsi Kendala di atas, data diolah menggunakan software $Q M$ for Windows dengan pemilihan menu Integer \& Mixed Integer Programming dan memasukan nilai-nilai fungsi tujuan memaksimalkan dan fungsi kendala pada gambar sebagai berikut :

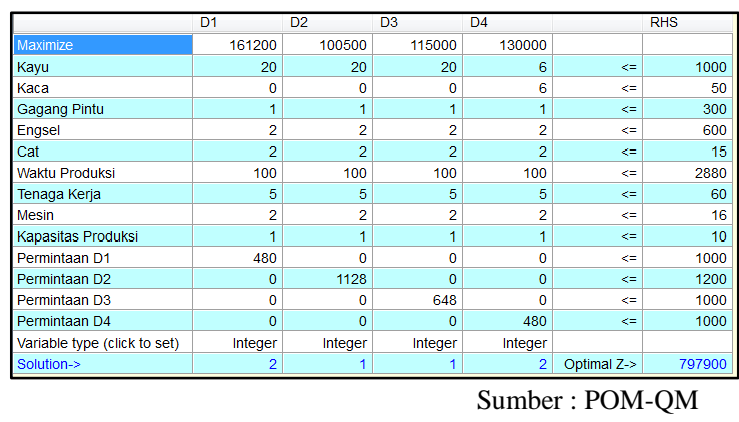

Gambar 1. Original Problem Table With Solution

Pada gambar di atas dapat dilihat bahwa tiap variabel keputusan dibatasi sebagai bilangan bulat (integer). Sebelum solusi tersebut terdapat hasil iterasi yang didapat sebagai berikut: 


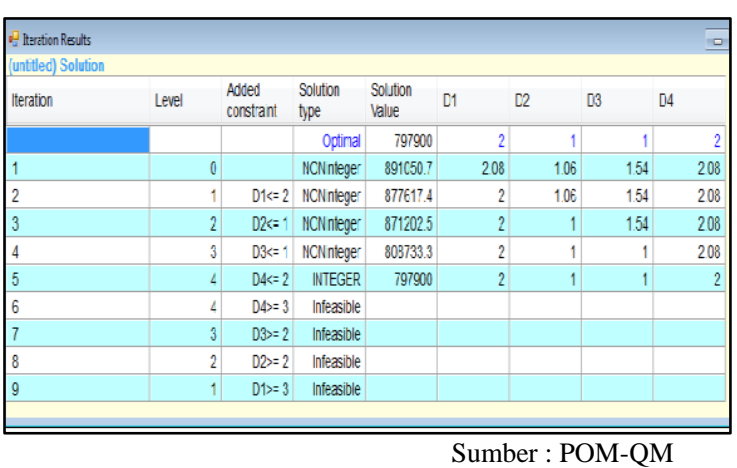

Gambar 2. Iteration Result

Dari hasil iterasi tersebut sebanyak 4 kali iterasi dan dinyatakan integer, didapatlah hasil percabangan yaitu sebagai berikut:

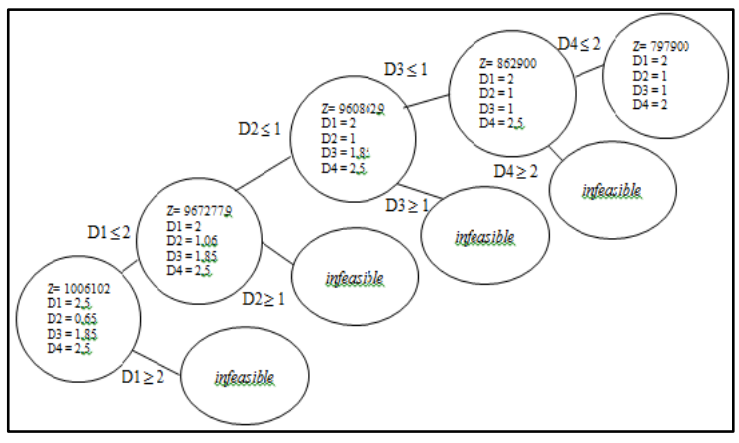

Sumber: Penelitian

Gambar 3. Hasil Percabangan

Berdasarkan pengolahan data di atas didapatkan hasil produksi dan penjualan yang optimal dengan keterbatasan sumber daya yang tersedia pada proses percabangan tersebut terakhir di iterasi ke9 dimana hasil dari iterasi tersebut memperoleh hasil yang tidak layak dan nilai kurang dari batas bawah sehingga tidak dapat dilakukan percabangan lagi. Diperoleh percabangan yang optimal pada iterasi ke-4 dengan penambahan kendala yakni $\mathrm{D}_{4} \leq 2$ dengan nilai:

$\mathrm{D} 1=2, \mathrm{D} 2=1, \mathrm{D} 3=1$, dan $\mathrm{D} 4=2$.

Lalu disubstitusikan nilai tersebut :

$=161.200(2)+100.500(1)+115.000(1)$

$+130.000(2)=\operatorname{Rp} 797.900$

Berdasarkan fungsi tujuan tersebut, diperoleh informasi sebagai berikut: laba yang diperoleh dari produksi pintu tipe D1 sebesar Rp 322.400 per unit, pintu D2 sebesar Rp 100.500 per unit, pintu tipe D3 sebesar Rp 115.000 per unit dan pintu tipe D4 sebesar Rp 260.000 per unit tiap hari untuk memaksimalkan keuntungan dengan total keseluruhan keuntungan yang diterima PT XYZ dari semua tipe yaitu Rp 797.900 per hari. Jika dibandingkan dengan keuntungan sebelumnya yaitu $\mathrm{Rp}$. 506,700 namun setelah menggunakan algoritma Branch and Bound menjadi Rp. 797,900. Maka dapat dikatakan terjadinya peningkatan keuntungan setelah menggunakan algoritma Branch and Bound yaitu sebesar $36,5 \%$.

\section{SIMPULAN}

Dalam proses produksinya PT XYZ memiliki 13 kendala. Perencanaan produksi pada perusahaan dengan upaya memaksimalkan keuntungan menggunakan algoritma Branch and Bound cukup membantu untuk menjadi solusi dalam penentuan jumlah produksi untuk tiap-tiap tipe pintu, sehingga menghasilkan keuntungan yang maksimal. Berdasarkan pengolahan data menggunakan software QM for Windows didapatkan keuntungan maksimal sebesar Rp 797.900 dengan pintu tipe D1 memproduksi 2 unit, pintu tipe D2 memproduksi 1 unit, pintu tipe D3 memproduksi 1 unit, dan pintu tipe D4 memproduksi 2 unit. Dengan menggunakan algoritma Branch and Bound terjadi peningkatan keuntungan yaitu sebesar $36,5 \%$ dibandingkan keuntungan yang diperoleh perusahaan sebelumnya.

\section{DAFTAR PUSTAKA}

[1] S. Assauri, "Manajemen Produksi dan Operasi," Jakarta Lemb. Penerbit Fak. Ekon. Univ. Indones., 2008.

[2] Wayne L. Winston, Operations Research: Applications and Algorithms, Forth Edition. 2004. 
[3] A. Akram, A. Sahari, and A. I. Jaya, "Optimalisasi Produksi Roti dengan Menggunakan Metode Branch and Bound (Studi Kasus Pada Pabrik Roti Syariah Bakery, Jl. Maleo, Lrg.VIII No. 68 Palu)," J. Ilm. Mat. DAN Terap., 2016, doi: 10.22487/2540766x.2016.v13.i2.72 09.

[4] H. W. Jiao, F. H. Wang, and Y. Q. Chen, "An effective branch and bound algorithm for minimax linear fractional programming," J. Appl. Math., vol. 2014, 2014, doi: $10.1155 / 2014 / 160262$.

[5] H. P. Williams, "The problem with integer programming," IMA J. Manag. Math., vol. 22, no. 3, pp. 213-230, 2011, doi: 10.1093/imaman/dpq014.

[6] Y. N. Firdaus, N. L. Buyung, A. Hermansyah, R. Nurhadiyati, I. Falani, and E. Wiratmani, "Implementasi Algoritma Branch and Bound dalam Penentuan Jumlah Produksi untuk Memaksimalkan Keuntungan," STRING (Satuan Tulisan Ris. dan Inov. Teknol., 2019, doi: 10.30998/string.v4i1.3717.
[7] I. Falani, "Penentuan Nilai Parameter Metode Exponential Smoothing Dengan Algoritma Genetik Dalam Meningkatkan Akurasi Forecasting," Comput. Eng. Sci. Syst. J., vol. 3, no. 1, p. 14, 2018, doi: 10.24114/cess.v3i1.8268.

[8] E. Mehdizadeh and S. Jalili, "An algorithm based on theory of constraints and branch and bound for solving integrated product-mixoutsourcing problem," J. Optim. Ind. Eng., vol. 12, no. 1, pp. 167172, 2019, doi: 10.22094/JOIE.2018.664.1429.

[9] B. W. Taylor, Introduction to Management Science 11e, vol. 58, no. 3. 2013.

[10] D. Reyniers and H. A. Taha, "Operations Research: An Introduction (4th Edition)," The Journal of the Operational Research Society, vol. 40, no. 11. p. 1054, 1989, doi: 10.2307/2583144. 